\title{
Analisis Pengaruh Heat Treatment terhadap Sifat Mekanik dan Ketahanan Korosi Intergranular SA-240 TP316L
}

\author{
Adhi Setiawan ${ }^{1 *}$, Puguh Pribadhi ${ }^{2}$, Muhamad Ari ${ }^{3}$ \\ ${ }^{1,2,3}$ Politeknik Perkapalan Negeri Surabaya \\ *adhistw23@gmail.com
}

\begin{abstract}
Intergranular corrosion is a problem that often occurs in welding stainless steel materials. Intergranular corrosion is caused by carbide precipitation which occurs at a temperature of $850^{\circ} \mathrm{C}$, causing a reduction in chromium content in the Heat Affected Zone (HAZ). The intergranular corrosion process can be controlled by the heat treatment method after the welding process. This study aims to study the effect of heat treatment on mechanical properties and intergranular corrosion resistance of SA240 TP316L material. The variation of heat treatment were divided into three solution treatment (ST), quenching treatment $(Q C)$, and non-treatment (NT). Mechanical properties testing using tensile test while corrosion resistance testing using linear polarization using $\mathrm{H}_{2} \mathrm{SO}_{4} 0.1 \mathrm{M}$ solution. Morphology and metal composition in the HAZ area were analyzed using SEM-EDX. Tensile test results showed that welding with ST had the lowest yield strength, ultimate strength, and elongation values compared to specimens of $407.55 \mathrm{MPa}, 599.33 \mathrm{MPa}$, and 44.53\%. Corrosion test results found that welding with solution treatment has the lowest corrosion rate compared to specimens with quenching treatment $(Q C)$ and non treatment (NT). Corrosion rate in each ST, QC, and NT specimens was 0.90; 1.03; and 2.35 mmpy. The results showed that the solution treatment process can improve intergranular corrosion resistance.
\end{abstract}

Keywords :stainless steel, intergranular corrosion, solution treatment.

\begin{abstract}
Abstrak
Korosi intergranular merupakan permasalahan yang sering terjadi pada pengelasan material baja tahan karat. Korosi intergranular disebabkan oleh presipitasi karbida yang terjadi pada suhu sekitar $850^{\circ} \mathrm{C}$ sehingga menyebabkan berkurangnya kandungan krom di bagian Heat Affected Zone (HAZ). Proses korosi intergranular dapat dikendalikan dengan metode heat treatment setelah proses pengelasan. Penelitian ini bertujuan untuk mempelajari pengaruh heat treatment terhadap sifat mekanik dan ketahanan korosi intergranular material SA240 TP316L.Variasi heat treatment dibagi menjadi tiga yaitu solution treatment $(\mathrm{ST})$, quenching treatment $(\mathrm{QC})$, dan non treatment $(\mathrm{NT})$. Pengujian sifat mekanik menggunakan tensile test sedangkan pengujian ketahanan korosi menggunakan polarisasi linear menggunakan larutan $\mathrm{H}_{2} \mathrm{SO}_{4} \quad 0,1 \mathrm{M}$. Morfologi dan komposisi logam pada daerah HAZ dianalisis menggunakan SEM-EDX. Hasil tensile test menunjukkan bahwa pengelasan dengan solution treatment memiliki nilai yield strength, ultimate strength, dan elongation terendah dibandingkan dengan spesimen yaitu 407,55MPa, 599,33MPa, dan 44,53\%. Hasil uji korosi diketahui pengelasan dengan solution treatment memiliki laju korosi terendah dibandingkan dengan spesimen dengan quenching treatment (QC) dan non treatment (NT). Laju korosi pada masing-masing spesimen ST, QC, dan NT sebesar 0,90;1,03; dan 2,35 mmpy. Hasil penelitian menunjukkan bahwa proses solution treatment dapat memperbaiki ketahanan korosi intergranular.
\end{abstract}

Kata kunci :baja tahan karat, korosi intergranular, solution treatment

\section{Pendahuluan}

Stainless steel (baja tahan karat) type austenitic adalah salah satu tipe stainless steel yang sangat familiar dan termasuk non magnetic. Material tersebut memiliki kelebihan yaitu mudah dibentuk serta memiliki sifat mampu las yang cukup baik.Baja tahan karat austenitik banyak digunakan pada 
struktur teknik yang beroperasi pada suhu tinggi seperti material pipa superheater di boiler[1].

Pengelasan material stainless steel berbeda dengan pengelasan pada carbon steel. Permasalahan yang sering terjadi pada pengelasan stainless steel adalah korosi intergranular. Korosi intergranular yaitu korosi yang terjadi pada batas butir. Korosi intergranular pada baja tahan karat merupakan salah satu jenis korosi terlokalisasi. Pada saat baja tahan karat terserang korosi intergranular, permukaan logam masih terlihat sangat cerah dan mulus tetapi mudah sekali rapuh terhadap tekanan luar. Korosi intergranular cukup sulit terdeteksi secara visual dan menyebabkan peralatan rusak secara tiba-tiba [2].Korosi intergranular dari baja tahan karat dapat diamati pada bagian sambungan pengelasan dengan suhu antara 500 dan $850^{\circ} \mathrm{C}[1]$. Korosi intergranular terjadi karena deplesi kromium pada batas butir yang disebabkan kromium karbida $\left(\mathrm{Cr}_{23} \mathrm{C}_{6}\right)$. Ketika baja tahan karat austenitic terpapar dalam waktu yang lama pada suhu antara 500 dan $850^{\circ} \mathrm{C}$ terjadi proses presipitasi karbida. Sejumlah besar fase selain $\mathrm{Cr}_{23} \mathrm{C}_{6}$ terbentuk antara lain $\mathrm{Cr}_{6} \mathrm{C}$ dan fase sigma, fase intermetalik chi dan laves[3]. Fase sigma yang terbentuk memiliki kandungan kromium dan molybdenum yang lebih tinggi dibandingkan dengan fase austenite sehingga presipitasi di batas butir menyebabkan deplesi unsur-unsur tersebut pada bagian matriksnya.

Beberapa usaha dapat dilakukan untuk meningkatkan ketahanan korosi intergranular pada baja tahan karat antara lain mengurangi komposisi karbon, mengubah komposisi logam, meningkatkan ukuran butir kristal, meningkatkan waktu proses sensitasi dan desinsitasi [4]. Penurunan kadar karbon kurang dari $0,03 \%$ pada baja tahan karat tipe AISI 304L dan 316L dapat menekan terjadinya korosi intergranular namun hal tersebut dapat menurunkan yield strength austenite pada kondisi annealing.

Beberapa peneliti telah melaporkan terkait permasalahan korosi intergranular pada baja tahan karat.Terada dkk.[5] dalam penelitiannya melaporkan bahwa pengaruh presipitasi terhadap ketahanan korosi baja tahan karat AISI 316L(N) yang sebelumnya mengalami uji creep pada suhu $600^{\circ} \mathrm{C}$ selama 10 tahun. Hasil penelitian menunjukkan bahwa tingkat kerentanan korosi dipengaruhi oleh suhu aging dan waktu pengujian creep. Li dkk [4] melaporkan bahwa ukuran peningkatan ukuran butir kristal cenderung menurunkan derajat sensitasi yang menyebabkan korosi intergranular. Takei dkk [6] mempelajari pengaruh kondisi pendinginan terhadap ketahanan korosi intergranular dari UNS S32506 Duplex baja tahan karat. Proses quenching pada suhu di bawah $800^{\circ} \mathrm{C}$ setelah pendinginan udara dengan laju yang konstan dapat meningkatkan potensi korosi intergranular. Informasi tentang proses intergranular korosi akibat pengelasan material SA-240 TP316L belum dijelaskan secara detail pada peneliti sebelumnya. Penelitian ini bertujuan untuk mempelajari pengaruh perlakuan panas (heat treatment) pengelasan terhadap ketahanan korosi intergranular dan sifat mekanik material SA-240 TP316L.

\section{Metoda Penelitian \\ 2.1. Alat dan Bahan}

Bahan yang digunakan pada penelitian ini yaitu logam induk yang akan digunakan yaitu SA 240 TP $316 \mathrm{~L}$ sesuai dengan spesifikasi yang tertera pada ASME II A (A 240/A $240 \mathrm{M}$ ). Elektroda yang digunakan pada proses pengelasan yaitu menggunakan E316L-16. Data spesifikasi dan komposisi kimia SA 240 TP 316L disajikan pada Tabel 1 dan Tabel 2 [7]. Penelitian ini menggunakan peralatan las SMAW dengan polaritas Direct Current Reversed Polarity (DCRP). Peralatan digunakan sebagai pengujian antara lain tanur muffle (muffle furnace), alat ukur laju korosi potensiostat/galvanostat, uji tarik (tensile test), dan Scanning Electron Microscope-Energy Dispersive X-Ray Spectroscopy (SEM-EDX). 
Tabel 1. Spesikasi SA 240 TP 316L (ASME IIA, 2013)

\begin{tabular}{ll}
\hline Spesifikasi & Nilai \\
\hline Tensile strength (Mpa) & 485 \\
Yield strength (MPa) & 170 \\
Elongation 50 mm (in) & 40 \\
Hardness Brinell & 217 \\
\hline
\end{tabular}

Tabel 2. Komposisi kimia SA 240 TP 316L (ASME IIA, 2013)

\begin{tabular}{ll}
\hline Unsur & Komposisi (\%wt) \\
\hline Karbon (C) & 0,03 \\
Mangan (Mn) & 2,00 \\
Fosfor (P) & 0,45 \\
Belerang (S) & 0,03 \\
Silikon (Si) & 0,75 \\
Krom (Cr) & $16-18$ \\
Mangan (Mn) & $2-3$ \\
Nitrogen (N) & 0,1 \\
\hline
\end{tabular}

\subsection{Proses Pengelasan}

Dimensi material baja tahan karat yaitu sebesar $300 \mathrm{~mm}$ x $150 \mathrm{~mm}$ x $12 \mathrm{~mm}$. Desain sambungan yang digunakan adalah $\mathrm{V}$ joint dengan sudut sebesar $60^{\circ}$ serta root gap dan root face masing-masing $3 \mathrm{~mm}$ dan $2 \mathrm{~mm}$ seperti pada Gambar 1. Parameter pengelasan berdasarkan WPS No.S-8M-L61 (PT. Petrokimia Gresik) dengan mengacu pada ASME SECTION IX. Parameter pengelasan meliputi kuat arus 80-120 A, tegangan $30 \mathrm{~V}$, dan kecepatan 8-10 cm/menit.

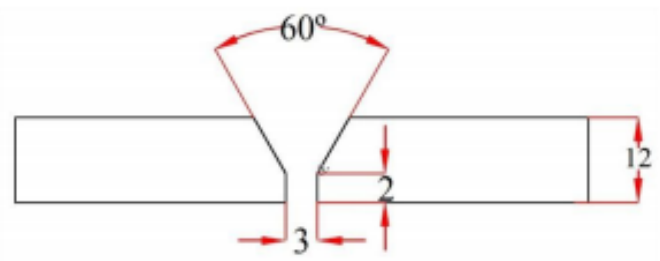

Gambar 1. Desain pengelasan dalam satuan $\mathrm{mm}$

Penelitian ini menggunakan tiga jenis perlakuan panas (heat treatment) pada proses pengelasan antara lain pengelasan dengan solution treatment (ST), Pengelasan dengan dengan quenching treatment pasca pengelasan (QT), dan pengelasan tanpa perlakuan panas (NT).

Metode solution treatment (ST) dilakukan dengan melakukan pengelasan sampai dengan suhu $1040^{\circ} \mathrm{Cdan}$ didinginkan dengan udara sampai dengan suhu normal. Hasil pengelasan tersebut selanjutnya dipanaskan kembali sampai dengan suhu $1040^{\circ} \mathrm{C}$ selama 15 menit di dalam mufflefurnace. Material selanjutnya didinginkan cepat menggunakan media pendingin air pasca pengelasan sampai suhunya mencapai $250^{\circ} \mathrm{C}$.Proses pengelasan dengan quenching treatment (QT) dilakukan dengan melakukan pengelasan sampai dengan suhu $1040^{\circ} \mathrm{Cdan}$ menerapkan tambahan quenching pasca pengelasan dengan disemprot air pada setiap pass-nya sampai suhu $250^{\circ} \mathrm{C}$ baru dilanjutkan pengelasan kembali. Pada sampel tanpa treatment (NT) pengelasan dilakukan sampai dengan suhu $1040^{\circ} \mathrm{C}$ dan dibiarkan dingin oleh udara.

\subsection{Analisis}

Kuat tarik spesimen di uji menggunakan peralatan Universal Testing Machine Shimadzu UH-600 KNI. Pengujian kuat tarik menggunakan Standar ASTM E-8 dengan spesimen uji seperti pada Gambar 2. Dimensi spesimen uji tarik disajikan pada Tabel 3. Pengujian tarik (tensile test) bertujuan untuk mengetahui sifat-sifat mekanik material seperti ultimate strength, elongation, dan yield point (ASME IX, 2013).

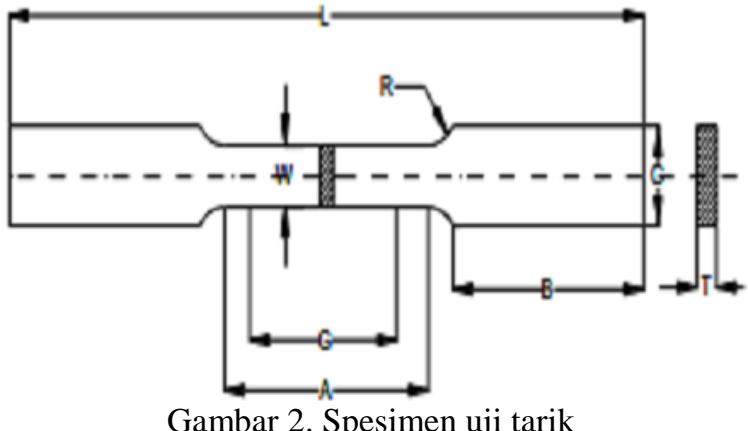

Tabel 3. Dimensi spesimen uji tarik

\begin{tabular}{lc}
\hline \multicolumn{1}{c}{ Keterangan } & Panjang (mm) \\
\hline Gage length (G) & 50 \\
Length of reduced section (A) & 57 \\
Width (W) & 12,5 \\
Thickness (T) & 10 \\
Radius of fillet (R) & 12,5 \\
Overall length (L) & 200 \\
Length of grip section (B) & 50 \\
Width of grip section (C) & 20 \\
\hline
\end{tabular}


Ketahanan korosi baja tahan karat pada variasi perlakuan panas dilakukan menggunakan metode polarisasi linear PGSTAT 32 METROHM) dengan elektroda reference berupa $\mathrm{Ag} / \mathrm{AgCl}$, elektroda counter berupa platina.Logam yang diuji sebagai elektroda kerja. Daerah las yang akan diuji adalah perpotongan melintang dari hasil pengelasan meliputi weld metal, base metal, dan Heat Affected Zone (HAZ). Larutan pengujian korosi menggunakan $\mathrm{H}_{2} \mathrm{SO}_{4}$ dengan konsentrasi larutan sebesar 0,1 M. Rapat arus korosi ( $\mathrm{I}_{\text {corr }}$ ) dapat diketahui pada pembacaan grafik polarisasi linear pengujian korosi sel tiga elektroda menggunakan metode Ekstrapolasi Tafel. Lalu laju korosi dapat dihitung dengan menggunakan rumus (1)berikut[8]:

$$
\mathrm{CR}=\frac{\mathrm{KI}_{\text {Corr }} \mathrm{EW}}{\rho}
$$

Keterangan:

$\mathrm{CR}=$ laju $\operatorname{korosi}(\mathrm{mmpy})$

$\mathrm{K}=3,27 \times 10^{-3} \mathrm{~mm} \cdot \mathrm{g} / \mu \mathrm{A} . \mathrm{cm} \cdot \mathrm{y}$

$\mathrm{I}_{\text {corr }}=$ rapat arus korosi $\left(\mu \mathrm{A} / \mathrm{cm}^{2}\right)$

$\mathrm{EW}=$ berat ekivalen spesimen $(\mathrm{g} / \mathrm{mol})$

$\rho \quad=$ densitas spesimen $\left(\mathrm{g} / \mathrm{cm}^{3}\right)$

Analisis morfologi dan komposisi kimia permukaan logam yang terkorosi intergranular dianalisis menggunakan metode SEM-EDX (Phenom desktop ProX).

\section{Hasil Penelitian}

Gambar 3 menunjukkan hasil uji tarik dari ketiga jenis variasi pengelasan yaitu solution treatment (ST), quenching pasca pengelasan (QT), dan pengelasan tanpa tambahan heat treatment (NT). Hasil pengujian yang disajikan pada Gambar 3 merupakan nilai rerata dengan intensitas empat pengujian pada setiap perlakuan. Hasil penelitian menunjukkan bahwa pengelasan tanpa tambahan heat treatment memiliki sifat mekanik yang lebih baik dibandingkan spesimen dengan perlakuan ST dan QT. Hal tersebut dapat diamati dari nilai parameter yield stress, ultimate stress, dan elongationmencapai nilai tertinggi pada kondisi tanpa tambahan perlakuan panas. Pada kondisi tesebut nilai yield stress, ultimate stress, dan elongation masing sebesar 407,55 $\mathrm{MPa}, 599,33 \mathrm{MPa}$, dan 44,53\%. Pengelasan dengan tambahan solution treatment memiliki nilai terendah pada yield stress, ultimate stress, dan elongation yaitu 304,56 Mpa, 557,70 MPa, dan34,25\%. Berdasarkan uji kekuatan tarik, benda yang telah mengalami perlakuan panas memiliki kekuatan yang menurun dibandingkan dengan benda sebelum mengalami perlakuan panas. Hal tersebut disebabkan karena butirankristal yang terbentuk menjadi besar. Butir yang besar akan membuat kekuatan baja menjadi rendah sehingga baja mudah putus [9].

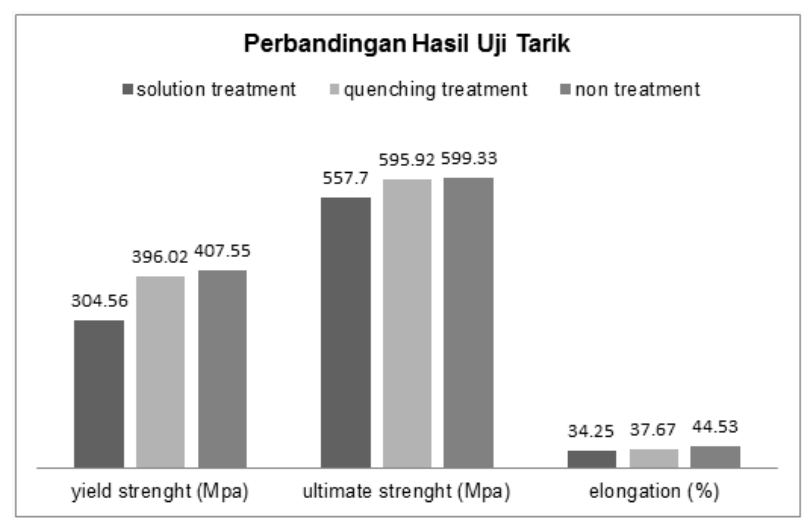

Gambar 3. Grafik hasil uji tarik (tensile test)

Herliansyah dan Dewo (2014) [10] melaporkan hasil penelitian yang serupa tentang pengaruh suhu annealing terhadap sifat mekanik dari baja tahan karat 316L. Proses annealing (pemanasan) menyebabkan peningkatan ukuran butir kristal (crystal grain) serta menurunkan jumlah butir kristal sehingga berpengaruh pada penurunan dislokasi di batas butir (grain boundary). Hal tersebut menyebabkan terjadinya penurunan sifat mekanik logam.

Tabel 4 menunjukkan hasil pengujian korosi baja tahan karat dengan variasi perlakuan panas.Hasil pengujian korosi menunjukkan bahwa spesimen ST memiliki nilai $\mathrm{I}_{\text {corr }}$ yang paling rendah dibandingkan dengan spesimen QT dan NT. Besarnya laju korosi spesimen ST diperoleh sebesar 0,9 mmpy. Hal tersebut mengindikasikan bahwa 
ketahanan korosi spesimen ST lebih baik dibandingkan dengan specimen QT dan NT. Proses ST dengan pemanasan tambahan sampai suhu $1040^{\circ} \mathrm{C}$ cenderung menyebabkan ukuran butir kristal meningkat. Li dkk. [5] melaporkan bahwa ukuran butir mempengaruhi waktu untuk memulai sensitisasi dan untuk mencapai sensitisasi lengkap. Peningkatan ukuran butir kristal dapat menunda timbulnya sensitisasi karena butir dengan ukuran besar memiliki zona penurunan kromium yang lebih luas dan konsentrasi kromium batas butir yang lebih rendah. Studi tentang pengukuran tingkat sensitisasi dan perilaku presipitasi $\mathrm{Cr}_{23} \mathrm{C}_{6}$ pada stainless steel menunjukkan bahwa proses sensitisasi dipercepat ketika ukuran butir semakin kecil. Selain itu, proses heat treatmentpada sampel ST dapat menyebakan pelarutan kembali kromium karbida pada batas butir (grain boundary). Bahkan, dengan proses pendinginan cepat setelah proses heat treatment dapat menekan proses sensitasi yang mengarah pada peningkatan ketahanan korosi intergranular [11].

Tabel 4. Hasil analisis polarisasi linier

\begin{tabular}{ccc}
\hline Spesimen & Icorr $\left(\mu \mathrm{A} / \mathrm{cm}^{2}\right)$ & CR $(\mathrm{mmpy})$ \\
\hline ST & 40,27 & 0,90 \\
QT & 46,28 & 1,03 \\
NT & 105,11 & 2,35 \\
\hline
\end{tabular}

Gambar 4 menunjukkan tidak adanya indikasi korosi intergranular pada sampel ST karena tidak adanya indikasi berupa penebalan pada batas butir di daerah HAZ (Heat Afected Zone). Pada sampel QT menunjukkan terdapat sedikit penebalan pada batas butir di daerah HAZ (Heat Afected Zone) yang merupakan indikasi terjadinya korosi intergranular sedangkan pada sampel NT menunjukkan terdapat banyak sekali penebalan pada batas butir di daerah HAZ (Heat Afected Zone) yang merupakan indikasi terjadinya korosi intergranular.

Hasil SEM baja tahan karat 316L setelah pengujian korosi. Daerah dengan penebalan dapat mengindikasikan tingkat kerusakan akibat korosi intergranular. Hasil pengamatan secara visual menunjukkan bahwa penebalan area batas butir pada spesimen NT cenderung lebih banyak terlihat dibandingkan dengan spesimen ST dan QC. Hal ini menunjukkan bahwa proses heat treatment setelah pengelasan disertai dengan pendinginan cepat menghasilkan ketahanan korosi intergranular yang lebih baik dibandingkan sampel yang hanya mengalami quenching (QC) dan tanpa treatment (NT). Proses heat treatment dapat memungkinkan larutnya (dissolution) kromium karbida $\left(\mathrm{Cr}_{23} \mathrm{C}_{6}\right)$ yang terbentuk pada batas butir akibat proses pengelasan [12].

Komposisi kimia pada batas butir di daerah HAZ (Heat Afected Zone) hasil analisis menggunakan EDX dapat disajikan pada Tabel 5.

Tabel 5. Hasil analisis EDX

\begin{tabular}{cccc}
\hline \multirow{2}{*}{ Unsur } & \multicolumn{3}{c}{ konsentrasi (\%) } \\
\cline { 2 - 4 } & ST & QT & NT \\
\hline Karbon (C) & 1,1 & 0,7 & 9,3 \\
Krom (Cr) & 17,5 & 15,2 & 3,8 \\
Besi (Fe) & 56,6 & 60,4 & 14,7 \\
Oksigen (O) & 12,9 & 9,5 & 47,1 \\
Lain-lain & 11,9 & 14,2 & 25,1 \\
\hline
\end{tabular}

Hasil analisis EDX pada variasi pengelasan tanpa heat treatment memiliki kandungan kromium yang paling rendah dibanding kedua sampel lain serta persentase carbon (C) yang paling tinggi dan dikarenakan adanya presipitasi karbida krom $\left(\mathrm{Cr}_{23} \mathrm{C}_{6}\right)$. Persentase kandungan oksigen $(\mathrm{O})$ pada hasil pengelasan tanpa heat treatment(NT) paling tinggi dibandingkan dengan spesimen ST dan NT. Kandungan unsur oksigen berasal dari produk korosi berupa oksida logam. Berdasarkan hasil SEM-EDX menunjukkan bahwa spesimen hasil pengelasan tanpa heat treatment (NT) memiliki tingkat kerentanan terhadap korosi intergranular lebih tingi dibandingkan spesimen dengan solution treatment $(\mathrm{ST})$ dan quenching treatment (QC). 


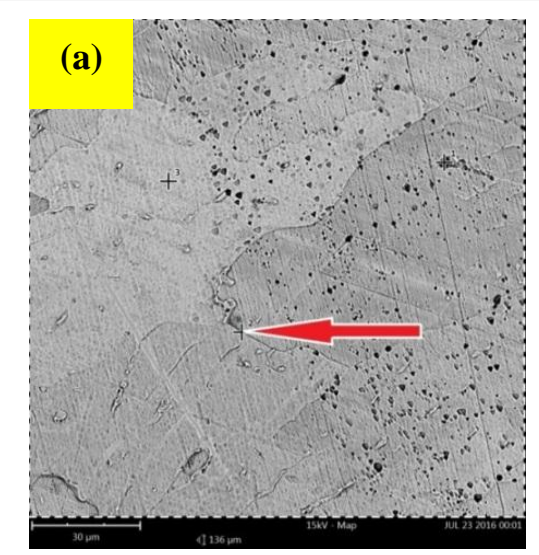

(b)
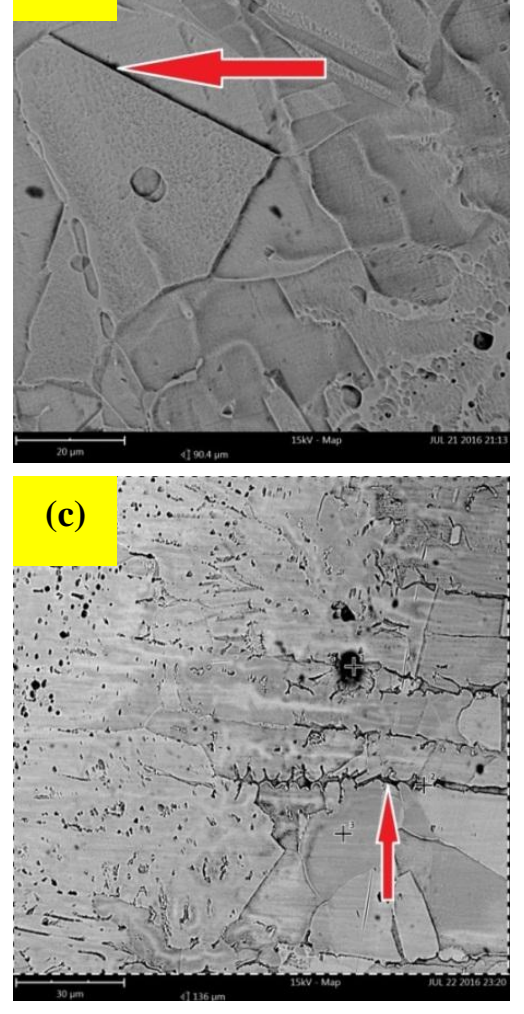

Gambar 4. Morfologi korosi intergranular pada spesimen (a) ST (b) QT dan (c) NT

\section{Kesimpulan}

Proses heat treatment pada proses pengelasan berpengaruh pada sifat mekanik dan ketahanan korosi intergranular logam SA 240 TP 316L. Hasil penelitian menunjukkan bahwa proses perlakuan menggunakan solution treatment (ST) setelah proses pengelasan cenderung menghasilkan sifat kekuatan tarik yang relatif lebih rendah dibandingkan dengan quenching treatment (QC) dan tanpa treatment (NT). Spesimen pengelasan dengan metode solution treatment memiliki nilai yield strength, ultimate strength, dan elongation yaitu $304,56 \mathrm{MPa}$, 557,70MPa, dan 34,25\%. Sampel dengan tambahan metode quenching pasca pengelasan memiliki yield strength, ultimate strength, dan elongation yaitu 396,02 MPa, $595,92 \mathrm{MPa}$, dan 37,67\%. Hasil pengujian tarik spesimen tanpa heat treatment memiliki yield strength, ultimate strength, dan elongation tertinggi yaitu $407,55 \mathrm{MPa}$, $599,33 \mathrm{MPa}$, dan 44,53\%. Proses solution treatment dapat memperbaiki ketahanan korosi intergranular. Hasil pengujian pengujian polarisasi linear menunjukkan bahwa $\mathrm{I}_{\text {corr }}$ dan laju korosi terendah dicapai dengan spesimen dengan solution treatment yaitu sebesar $40,27 \mu \mathrm{A} / \mathrm{cm}^{2}$ dan 0,9 mmpy.

\section{Saran}

Diperlukan adanya penelitian lebih lanjut mengenai pengaruh pengelasan terhadap sifat mekanik seperti tingkat kekerasan material serta pengaruh heat treatment terhadap perubahan ukuran grain dan komposisi fasa dari material sebelum dan setelah pengelasan.

\section{Daftar Pustaka}

[1] M. Laleh, A.E. Hughes, W. Xua, N. Haghdadib, K. Wang, P. Cizek, I. Gibsona, and M.Y. Tan, "On the Unusual Intergranular Corrosion Resistance of $316 \mathrm{~L}$ Stainless Steel Additively Manufactured by Selective Laser Melting," Corrosion Science, vol. 161, pp. 1081-1089, 2019

[2] S. Lin, W. Bao, J. Gao, and J. Wang, "Intergranular Corrosion of Austenitic Stainless Steel," Applied Mechanics and Materials, vol. 229-231, no.2012, pp 1417,2012

[3] Z. Stonawská, M. Svoboda, M. Sozańska, M. Kř́stková, J. Sojka C, Dagbert, and L. Hyspecká," Structural Analysis and Intergranular Corrosion Tests of AISI 316L Steel," Journal of Microscopy, vol. 224, no. 1, pp. 62-64, 2006 
[4] S. Li, Y. He, S. Yu, and P. Zhang, "Evaluation of The Effect of Grain Size on Chromium Carbide Precipitation and Intergranular Corrosion of 316L Stainless Steel," Corrosion Science, vol. 66, pp. 211-216, 2013

[5] M. Terada, D.M. Escriba, I. Costa, E. Materna-Morris, and A.F. Padilha, "Investigation on the Intergranular Corrosion Resistance of the AISI 316L(N) Stainless Steel After Long Time Creep Testing at $600{ }^{\circ} \mathrm{C}$," Materials Characterization, vol. 59, pp. 663-668, 2008

[6] T. Takei, M. Yabe, and F. Wei, "Effect of Cooling Condition on the Intergranular Corrosion Resistance of UNS S32506 Duplex Stainless Steel," Corrosion Science, vol. 122, pp. 80-89, 2017

[7] ASME Sec. II Part A, Ferrous Material Specifications. New York: USA, 2013

[8] A. Setiawan, "Sintesis dan Karakterisasi $\mathrm{ZnO}$ sebagai Coating Antikorosi $\mathrm{ZnO} / \mathrm{Al}(\mathrm{OH})_{3}$ pada Material Baja Karbon," Jurnal Teknik, vol. 39, no.1, pp. 55-61, 2018

[9] R. Rubijanto, "Pengaruh Proses Pendinginan Paska Perlakuan Panas Terhadap Uji Kekerasan (Vickers ) dan Uji Tarik Pada Baja Tahan Karat 304 Produksi Pengecoran Logam di Klaten," Jurnal Traksi, vol. 4, no.1, pp. 12-19, 2006

[10] M.K. Herliansyah, P. Dewo, M.H.N.E. Soesatyo, and W. Siswomihardjo, "The Effect of Annealing Temperature on the Physical and Mechanical Properties of Stainless Steel 316L for Stent Application," in International Conference on Instrumentation, Communications, Information Technology, and Biomedical Engineering, 2015, pp. 22-26
[11] X. Yu, S. Chen, Y. Liu, and F. Ren, "A Study of Intergranular Corrosion of Austenitic Stainless Steel by Electrochemical Potentiodynamic Reactivation, Electron Back-Scattering Diffraction and Cellular Automaton," Corrosion Science, vol. 52, pp. 19391947, 2010

[12] F. J. G. Silva, J. Santos and R. Gouveia, "Dissolution of Grain Boundary Carbides by the Effect of Solution Annealing Heat Treatment and Aging Treatment on Heat-Resistant Cast Steel HK30," Metals, vol. 7, no.2, pp. 1-12, 2017 